\title{
TARIFA BINÔMIA PARA O CUSTO DE ÁGUA PRESSURIZADA EM PERÍMETROS IRRIGADOS ${ }^{1}$
}

\author{
MARCOS C. RIBEIRO ${ }^{2}$, DELLY OLIVEIRA FILHO ${ }^{3}$, ANTÔNIO A. SOARES ${ }^{4}$, \\ JOSÉ H. MARTINS ${ }^{5}$, EVERARDO C. MANTOVANI ${ }^{6}$
}

\begin{abstract}
RESUMO: Nos distritos de irrigação, a tarifa de custo variável tem dependido exclusivamente da quantidade de água consumida e não, da energia e da demanda de potência elétrica para o fornecimento de água na pressão e na vazão recomendadas pelo sistema de irrigação. Essa forma de tarifação da água de irrigação é um contrassenso em que os irrigantes mais eficientes subsidiam os irrigantes menos eficientes. Este trabalho propõe que as tarifas de água considerem não somente a quantidade de água consumida no mês, mas também a pressão, já que a demanda de potência hidráulica é função do produto da vazão pela pressão de serviço. O estudo comparou o custo de água de irrigantes que consomem o mesmo volume mensal para a situação atual e pela metodologia proposta. Verificou-se, também, o efeito de irrigações isoladas ou simultâneas e sua implicação no custo da água. Os resultados mostraram que a implementação de tarifa binômia para a água pode reduzir o custo da água para o irrigante de baixa pressão em até $66 \%$. Já para os irrigantes com alta pressão, poderá ter acréscimo de até $133 \%$. A simultaneidade de uso da água também influencia seu custo devido à variação na demanda de potência de energia elétrica.
\end{abstract}

PALAVRAS-CHAVE: tarifa, distribuição de água, perímetro irrigado.

\section{WATER TARIFFS IN IRRIGATION DISTRICTS}

ABSTRACT: In irrigation districts, the variable cost tariff have being depended only on the amount of water consumed, and not in the energy and the demand for electric power to supply the water pressure and flow rate recommended by the irrigation system. This way of charge the irrigation water is nonsense, since the less efficient participants subsidized the more efficient ones. Thus, this work proposes that the water tariffs not only consider the amount of water consumed in the month, but also the pressure, since the hydraulic power demand is a function of the product of flow rate times the pressure. The study compared the water cost for participants that consume the same amount monthly for the present situation and the proposed methodology. It was verified, also, the effect of isolated irrigations or simultaneous ones and their implications on the water costs. The results showed that the implementation water tariff that charges the volume of water may reduce the costs for the participants at low pressures up to $66 \%$. On the other hand, high pressure participants may have their water bill increased up to $133 \%$. The simultaneity on the water use also influences its cost due to electrical power demand variation.

KEYWORDS: water tariff, distribution, irrigated perimeter.

\section{INTRODUÇÃO}

Os sistemas de irrigação pressurizados são classificados em três tipos, conforme a pressão utilizada: sistemas de alta pressão (aspersor canhão), de média pressão (aspersão convencional) e de baixa pressão (sistemas localizados). Em perímetros irrigados, normalmente, a conta de água, que traz embutida a conta de energia elétrica, é rateada pelo volume consumido de água por irrigante,

\footnotetext{
${ }^{1}$ Artigo extraído da tese do primeiro autor.

${ }^{2}$ Engo Agrícola, D.S. , Instituto Federal do Sul de Minas, Câmpus Inconfidentes, marcos.ribeiro@ifs.ifsuldeminas.edu.br.

${ }^{3}$ Eng ${ }^{\mathrm{O}}$ Eletricista, Prof. Associado, Depto. de Engenharia Agrícola, Universidade Federal de Viçosa, Viçosa - MG, delly@ufv.br.

${ }^{4}$ Eng ${ }^{\circ}$ Agrícola, Prof. Titular, Depto. de Engenharia Agrícola, Universidade Federal de Viçosa, Viçosa - MG, aasoares@ ufv.br.

${ }^{5}$ Eng ${ }^{\mathrm{O}}$ Agrícola, Prof. Titular, Depto. de Engenharia Agrícola, Universidade Federal de Viçosa, Viçosa - MG, jhmartins@ufv.br.

${ }^{6}$ Eng ${ }^{\circ}$ Agrícola, Prof. Titular, Depto. de Engenharia Agrícola, Universidade Federal de Viçosa, Viçosa - MG, everardo@ufv.br.

Recebido pelo Conselho Editorial em: 2-7-2009

Aprovado pelo Conselho Editorial em: 19-3-2010
} 
independentemente da pressão necessária à satisfação de cada sistema de irrigação em particular. No entanto, maior pressão significa maior consumo de energia elétrica $(\mathrm{kWh})$ e maior demanda de potência $(\mathrm{kW})$, resultando em maiores custos. Como os irrigantes que utilizam maior pressão são, em verdade, subsidiados pelos que utilizam menor pressão, o subsídio resulta em baixa eficiência de uns em prejuízo de outros.

Em relação à água, os irrigantes que necessitam de maior pressão, também consomem mais água, sendo oportuno citar que o Art. 19 da LEI DAS ÁGUAS estabelece que a água é um bem econômico e que a cobrança de seu uso objetiva dar ao usuário uma indicação de seu real valor, bem como incentivar o seu uso racional (BRASIL, 1997).

A tarifa de eletricidade aplicada à irrigação é binômia horo-sazonal (DNAEE, 1988), ou seja, há a conta de consumo de energia $(\mathrm{kWh})$ e a conta de demanda de potência $(\mathrm{kW})$ com preços diferenciados para os diferentes períodos do dia e para as estações seca (maio a novembro) e úmida (dezembro a abril). Esse tipo de tarifação busca otimizar o consumo de energia elétrica incentivando o consumo em horários e épocas de menor demanda ou de maior oferta.

Buscando a otimização de seus serviços, algumas empresas, como as de telefonia, de eletricidade, de transporte e de saneamento urbano, preveem tarifas diferenciadas em diferentes períodos do dia, pela distância percorrida ou pela localização (COSTA, 2001; OLIVEIRA FILHO et al., 2000; TANABE, 1998).

TURCO et al. (2009) avaliando sistemas de plantio direto e convencional, encontraram praticamente os mesmos valores de consumo e de custos com energia elétrica tanto para a tarifa horo-sazonal verde quanto para a azul.

Avaliando a eficiência do uso da energia elétrica em perímetro irrigado, no norte de Minas Gerais, MEDEIROS et al. (2003) concluíram sobre a importância da implantação de um programa que visa a sistematização do manejo da irrigação, buscando otimizar de forma integrada os recursos água e energia elétrica.

A tarifa cobrada do irrigante pela Administração do Perímetro, pelo metro cúbico de água, nem sempre corresponde ao valor atual, podendo ter sido programada para o ano agrícola (RIBEIRO, 2003).

Assim, neste trabalho, teve-se o objetivo de desenvolver metodologia para a proposição de uma tarifa binômia para a água consumida na irrigação pressurizada em perímetros irrigados, visando à obtenção de maior eficiência no uso de água e maior justiça no rateio da conta de energia elétrica.

\section{MATERIAL E MÉTODOS}

Este estudo foi realizado no Laboratório de Energia e no Laboratório de Hidráulica, pertencentes à área de Energia na Agricultura e à área de Recursos Hídricos e Ambientais, respectivamente, do Departamento de Engenharia Agrícola da Universidade Federal de Viçosa, em Viçosa - MG. Para a simulação do uso de água em lotes individuais no perímetro irrigado, foram utilizadas informações técnicas fornecidas pelo Distrito de Irrigação do Perímetro Irrigado de Mirorós - DIPIM, da cidade de Ibipeba - BA.

Para a escolha de um sistema de irrigação, devem-se considerar as características de funcionamento e o custo. Na Tabela 1, são apresentadas algumas considerações quanto à escolha do sistema de irrigação. 
TABELA 1. Aspectos gerais a serem considerados na escolha do sistema de irrigação. General aspects to be considered for the choice of irrigation system.

\begin{tabular}{|c|c|c|c|c|c|c|c|c|c|}
\hline \multirow{2}{*}{$\begin{array}{l}\text { Sistemas } \\
\text { de Irrigação }\end{array}$} & \multicolumn{3}{|c|}{$\begin{array}{l}\text { Volume de Água Requerido } \\
\left(\mathrm{L} \mathrm{s}^{-1} \mathrm{ha}^{-1}\right)\end{array}$} & \multicolumn{3}{|c|}{$\begin{array}{l}\text { Consumo de Energia } \\
\text { Elétrica }\left(\mathrm{kWh} \mathrm{m}^{-3}\right)\end{array}$} & \multicolumn{3}{|c|}{$\begin{array}{c}\text { Eficiência do Sistema } \\
(\%)\end{array}$} \\
\hline & Baixo & Médio & Alto & Baixo & Médio & Alto & Baixo & Médio & Alto \\
\hline Superfície & & & $>1$ & $<0,3$ & & & $<75$ & & \\
\hline Aspersão & & $0,6-1$ & & & & $0,2-0,6$ & & $60-85$ & \\
\hline Localizada & $<0,7$ & & & & $0,1-0,4$ & & & & $>80$ \\
\hline
\end{tabular}

\section{Simulação da operação de perímetros irrigados}

\section{Simulação hidráulica}

Com o conhecimento da pressão e da vazão de cada tomada d'água, pode-se utilizar a metodologia aplicada ao estudo do consumo de energia elétrica.

A eq.(1) apresenta as semelhanças entre as propriedades relacionadas ao sistema de bombeamento para acoplamento direto motor e bomba que foram usadas nos cálculos.

$$
\text { * }\left(\frac{\mathrm{n}_{2}}{\mathrm{n}_{1}}\right)=\left(\frac{\mathrm{f}_{2}}{\mathrm{f}_{1}(1-\mathrm{s})}\right)=*\left(\frac{\mathrm{Q}_{2}}{\mathrm{Q}_{1}}\right)={ }^{*}\left(\frac{\mathrm{H}_{2}}{\mathrm{H}_{1}}\right)^{1 / 2}=\left(\frac{\mathrm{T}_{2}}{\mathrm{~T}_{1}}\right)^{1 / 2}=*\left(\frac{\mathrm{P}_{2}}{\mathrm{P}_{1}}\right)^{1 / 3}
$$

em que,

$\mathrm{n}$ - rotação ou velocidade do rotor;

f - frequência de trabalho do motor, $\mathrm{Hz}$;

$\mathrm{s}$ - escorregamento no motor elétrico, decimal;

Q - vazão, $\mathrm{m}^{3} \mathrm{~s}^{-1}$

$\mathrm{H}$ - altura manométrica, mca;

$\mathrm{T}$ - torque do motor, $\mathrm{Nm}$;

$\mathrm{P}$ - potência hidráulica, $\mathrm{W}$;

1 - subscrito referente ao valor nominal da máquina;

2 - subscrito referente ao valor a ser encontrado, e

*- relações de Rateau.

\section{Potência hidráulica na tomada d'água}

A água bombeada e distribuída a cada lote irrigado apresenta um consumo e uma demanda de energia para suprir as suas necessidades hídricas. Pode-se fazer analogia da pressão e da vazão correspondentes. Mudança da pressão ou da vazão no lote altera o consumo de energia elétrica na estação de bombeamento.

A potência mecânica necessária em cada lote foi calculada utilizando-se da eq.(2):

$$
\mathrm{P}_{\mathrm{m}}=0,736 \frac{\mathrm{Q} \mathrm{H}_{\mathrm{man}}}{270 \eta_{\mathrm{b}}}
$$

em que,

$\mathrm{P}_{\mathrm{m}}$ - potência mecânica, $\mathrm{kW}$;

$\mathrm{Q}$ - vazão, $\mathrm{m}^{3} \mathrm{~h}^{-1}$;

$\mathrm{H}_{\text {man }}$ - somatório das pressões das tomadas d'água a que a estação de bombeamento pertence, $\mathrm{m}, \mathrm{e}$

$\eta_{\mathrm{b}}$ - rendimento da bomba, decimal. 


\section{Medidas de gerenciamento e tarifas binômias}

A tarifa de energia elétrica binômia é função do consumo (kWh) e da demanda $(\mathrm{kW})$. Já, a tarifa de irrigação binômia como proposta à taxação foi caracterizada em função da vazão e da pressão, como apresentado na eq.(3):

$$
\mathrm{T}_{\text {irr }}=\mathrm{f}\left(\frac{\mathrm{Vol}}{\text { mês }}, \frac{\mathrm{P}}{\text { mês }}\right)
$$

em que,

$\mathrm{T}_{\text {irr }}$ - tarifa de irrigação, $\mathrm{R}$ \$ (mês) ${ }^{-1}$;

Vol - volume de água, $\mathrm{m}^{3}$, e

$\mathrm{P}$ - pressão, mca.

\section{RESULTADOS E DISCUSSÃO}

\section{Simulação da operação de perímetros irrigados}

Utilizando as relações de Rateau (BERNARDO et al., 2006), apresentadas na eq.(1), simulouse situação em que um ramal de um sistema de bombeamento fornece água para três irrigantes para determinada cultura, com mesmo volume diário e rendimento total de $100 \%$, ou seja, foram desconsideradas perdas no processo. O que difere os três irrigantes é o tipo de irrigação utilizado.

Os irrigantes 1 e 2 utilizam irrigação localizada (baixa pressão), e o irrigante 3 usa aspersão convencional (média pressão). Três situações foram analisadas, conforme Tabela 2 (a,b,c) e, de forma gráfica, nas Figuras $1(a, b, c)$ e $2(a, b, c)$. Em cada situação, houve rearranjo dos horários de irrigação. Em (a), a irrigação ocorre simultaneamente. Em (b), um dos irrigantes foi retirado para horário diferente, de forma a evitar o acúmulo e em (c), os três irrigantes operam separadamente no tempo.

A Tabela 2 compara em energia $(\mathrm{kWh})$, em potência elétrica $(\mathrm{kW})$ e em custo financeiro a situação atual, que é de rateio simples baseado na quantidade medida por hidrômetro na irrigação de cada lote, e a situação proposta, em que o rateio depende, também, da pressão necessária em cada lote. O valor da tarifa aplicada para a demanda de potência elétrica foi de $\mathrm{R} \$ 13,815 / \mathrm{kW}$ e para o consumo foi de $\mathrm{R} \$ 0,1121 / \mathrm{kWh}$ no período fora de ponta da concessionária de energia.

Na Figura 1(a), por rateio simples, cada irrigante pagaria $\mathrm{R} \$ 72,85$, em extrapolação para o período de um mês, enquanto, pela forma binômia proposta, os irrigantes 1 e 2 pagariam $\mathrm{R} \$ 46,35$ cada um e o terceiro irrigante pagaria 125,86 , ou seja, redução para baixa pressão e aumento para pressão mais elevada.

Na Figura 1(b), na forma convencional de tarifação, a parcela de cada um no rateio simples seria de $\mathrm{R} \$ 19,50$. Pela forma binômia, os dois primeiros pagariam $\mathrm{R} \$ 12,69$ cada um e o terceiro, $\mathrm{R} \$ 33,12$, novamente com redução para a baixa pressão e aumento para pressão mais elevada.

Na Figura 1(c), no rateio simples, cada um arcaria com o valor de $\mathrm{R} \$ 16,20$ e na tarifa binômia, os dois primeiros pagariam $\mathrm{R} \$ 5,46$ e o terceiro $\mathrm{R} \$ 37,69$.

Nas três situações, houve redução para os dois primeiros e aumento para o terceiro, conforme suas necessidades de pressão, ou seja, a forma de tarifação proposta mostra-se mais justa na tarifação de água para a irrigação em perímetros irrigados. 
TABELA 2. Gastos de energia elétrica representados pelas situações de uso da irrigação para uma mesma lâmina de irrigação. Electricity expenses for different irrigation management for a given water depth.

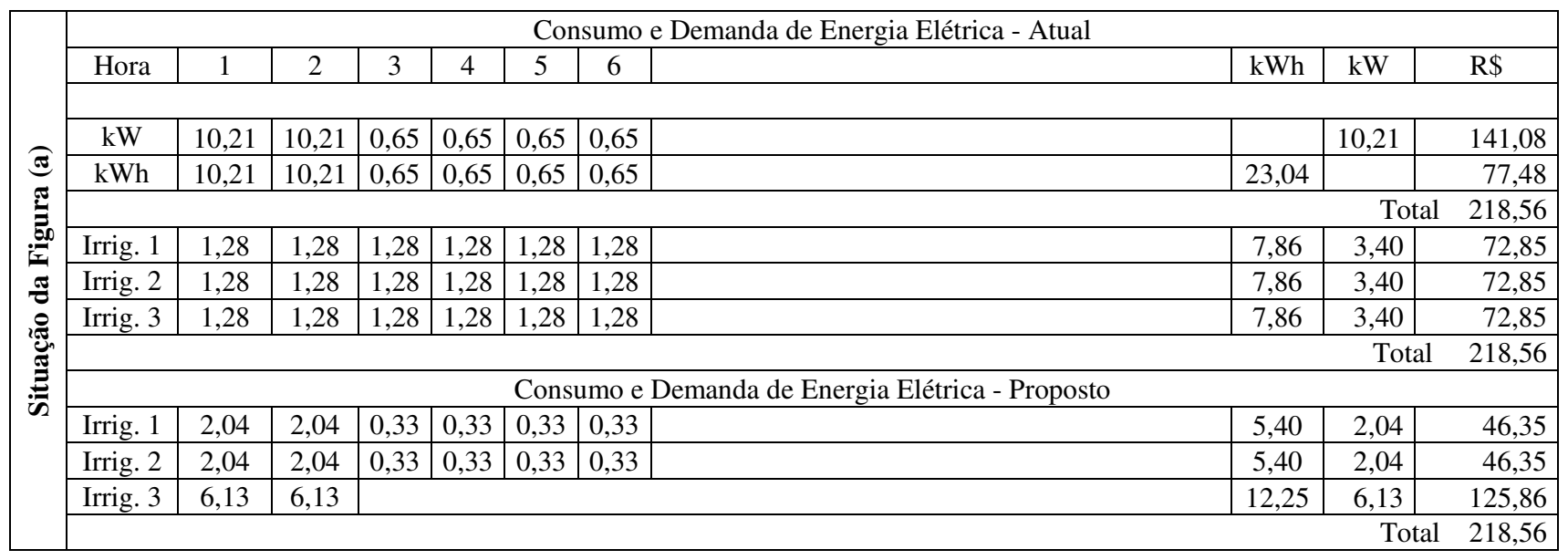

\begin{tabular}{|c|c|c|c|c|c|c|c|c|c|c|c|c|}
\hline & \multicolumn{12}{|c|}{ Consumo e Demanda de Energia Elétrica - Atual } \\
\hline & Hora & 1 & 2 & 3 & 4 & 5 & 6 & 7 & 8 & $\mathrm{kWh}$ & $\mathrm{kW}$ & $\mathrm{R} \$$ \\
\hline \multirow{12}{*}{ 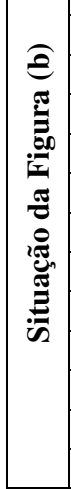 } & $\mathrm{kW}$ & 065 & 065 & 0.65 & 0.65 & 065 & 065 & 221 & 221 & & 221 & 30.47 \\
\hline & $\mathrm{kWh}$ & 0,65 & 0,65 & 0.65 & 0.65 & 0.65 & 0.65 & 2,21 & 2,21 & 8.33 & & 28,03 \\
\hline & \multicolumn{12}{|r|}{58,50} \\
\hline & Irrig. 1 & 0,35 & 0,35 & 0,35 & 0,35 & 0,35 & 0,35 & 0,35 & 0,35 & 2,78 & 0,74 & 19,50 \\
\hline & Irrig. 2 & 0,35 & 0,35 & 0,35 & 0,35 & 0,35 & 0,35 & 0,35 & 0,35 & 2,78 & 0,74 & 19,50 \\
\hline & Irrig. 3 & 0,35 & 0,35 & 0,35 & 0,35 & 0,35 & 0,35 & 0,35 & 0,35 & 2,78 & 0,74 & 19,50 \\
\hline & \multicolumn{12}{|c|}{ Total } \\
\hline & \multicolumn{12}{|c|}{ Consumo e Demanda de Energia Elétrica - Proposto } \\
\hline & Irrig. 1 & 0,33 & 0,33 & 0,33 & 0,33 & 0,33 & 0,33 & & & 1,98 & 0,44 & 12,69 \\
\hline & Irrig. 2 & 0,33 & 0,33 & 0,33 & 0,33 & 0,33 & 0,33 & & & 1,98 & 0,44 & 12,69 \\
\hline & Irrig. 3 & & & & & & & 2,21 & 2,21 & 4,42 & 1,32 & 33,12 \\
\hline & & & & & & & & & & & & 58,50 \\
\hline
\end{tabular}

\begin{tabular}{|c|c|c|c|c|c|c|c|c|c|c|c|c|c|c|c|c|c|c|}
\hline \multirow{14}{*}{ 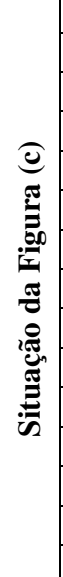 } & \multicolumn{18}{|c|}{ Consumo e Demanda de Energia Elétrica - Atual } \\
\hline & Hora & 1 & 2 & 3 & 4 & 5 & 6 & 7 & 8 & 9 & 10 & 11 & 12 & 13 & 14 & $\mathrm{kWh}$ & $\mathrm{kW}$ & Total R\$ \\
\hline & $\mathrm{kW}$ & 0,10 & 0,10 & 0,10 & 0,10 & 0,10 & 0,10 & 0,10 & 0,10 & 0,10 & 0,10 & 0,10 & 0,10 & 2,21 & 2,21 & & 2,21 & 30,47 \\
\hline & $\mathrm{kWh}$ & 0,10 & 0,10 & 0,10 & 0,10 & 0,10 & 0,10 & 0,10 & 0,10 & 0,10 & 0,10 & 0,10 & 0,10 & 2,21 & 2,21 & 5,39 & & 18,13 \\
\hline & \multicolumn{17}{|c|}{ Total } & 48,60 \\
\hline & Irrig. 1 & 0,13 & 0,13 & 0,13 & 0,13 & 0,13 & 0,13 & 0,13 & 0,13 & 0,13 & 0,13 & 0,13 & 0,13 & 0,13 & 0,13 & 1,80 & 0,74 & 16,20 \\
\hline & Irrig. 2 & 0,13 & 0,13 & 0,13 & 0,13 & 0,13 & 0,13 & 0,13 & 0,13 & 0,13 & 0,13 & 0,13 & 0,13 & 0,13 & 0,13 & 1,80 & 0,74 & 16,20 \\
\hline & Irrig. 3 & 0,13 & 0,13 & 0,13 & 0,13 & 0,13 & 0,13 & 0,13 & 0,13 & 0,13 & 0,13 & 0,13 & 0,13 & 0,13 & 0,13 & 1,80 & 0,74 & 16,20 \\
\hline & \multirow{2}{*}{\multicolumn{18}{|c|}{ Consumo e Demanda de Energia Elétrica - Proposto }} \\
\hline & & & & & & & & & & & & & & & & & & \\
\hline & Irrig. 1 & 0,10 & 0,10 & 0,10 & 0,10 & 0,10 & 0,10 & & & & & & & & & 0,49 & 0,28 & 5,46 \\
\hline & Irrig. 2 & & & & & & & 0,10 & 0,10 & 0,10 & 0,10 & 0,10 & 0,10 & & & 0,49 & 0,28 & 5,46 \\
\hline & Irrig. 3 & & & & & & & & & & & & & 2,21 & 2,21 & 4,42 & 1,65 & 37,69 \\
\hline & & & & & & & & & & & & & & & & & Tot & 48,61 \\
\hline
\end{tabular}




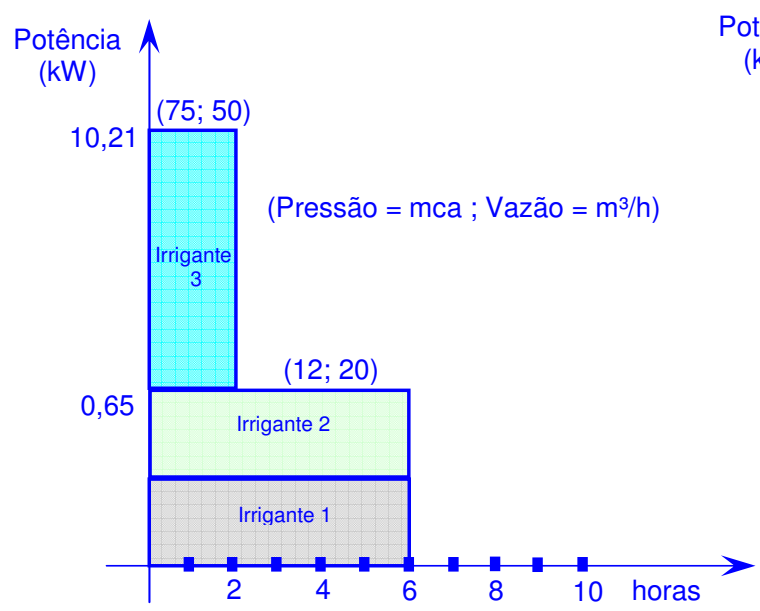

(a)

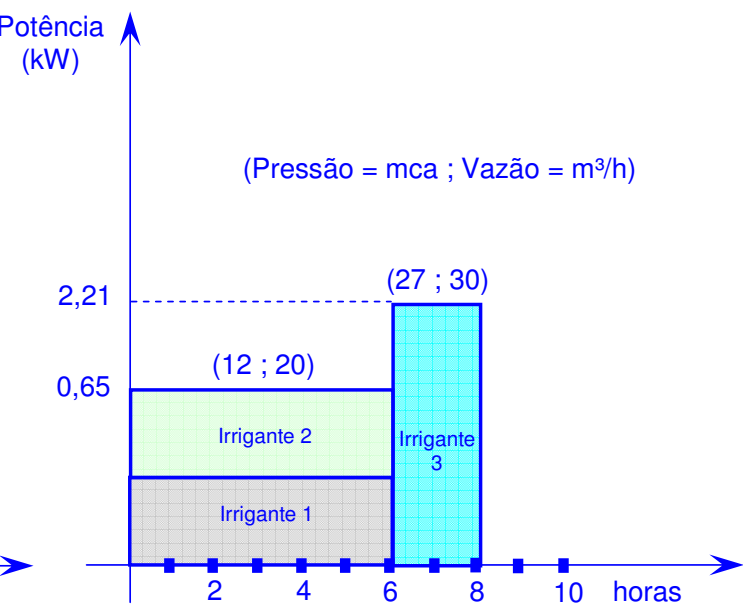

(b)

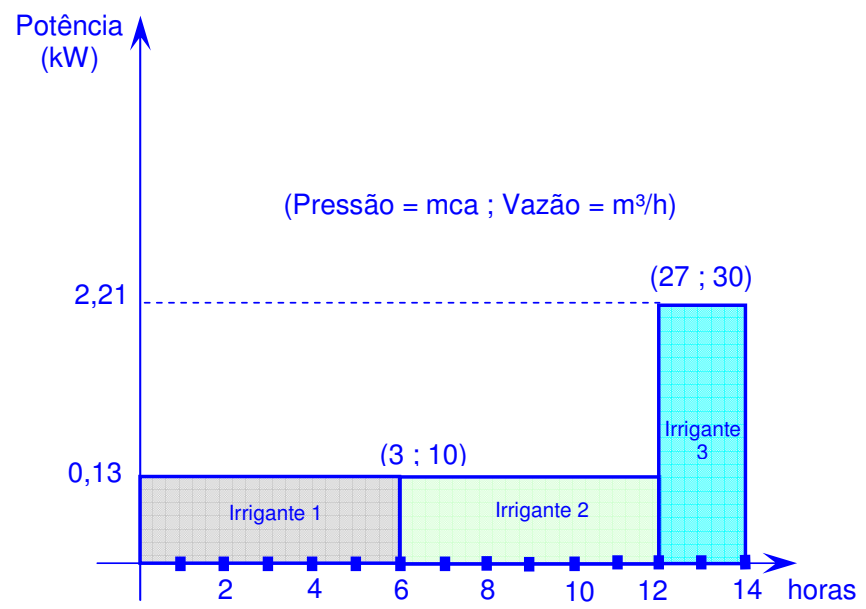

(c)

FIGURA 1. Representação gráfica de situações de uso de irrigação por três irrigantes, conforme Tabela 2. Graphical representation of irrigation use for three irrigating according to Table 2.

Na situação (a), os irrigantes 1 e 2 necessitam de maior tempo para a irrigação de sua área por usarem baixa pressão e vazão. Já, o irrigante 3, com sistema de alta pressão e vazão, pode irrigar sua área em menor tempo. A demanda de potência de energia elétrica nas duas primeiras horas atinge $10,21 \mathrm{~kW}$ ou R\$141,08, pois a conta mensal de demanda de potência elétrica corresponde ao pico máximo atingido no mês. No rateio simples da despesa como hoje é feito, cada um pagaria $\mathrm{R} \$ 47,03$ pela demanda de potência.

Extrapolando para um mês a despesa de consumo de energia elétrica, encontram-se R $\$ 77,48$ que, no rateio foi de $\mathrm{R} \$ 25,83$. A conta total, demanda e energia consumida, resultaria em $\mathrm{R} \$ 72,85$ para cada irrigante na forma do rateio simples, como hoje é feito. Da forma binômia, como proposta, levando-se em consideração a pressão de cada sistema de irrigação, os irrigantes 1 e 2 pagariam $\mathrm{R} \$ 46,35$ cada um, e o irrigante $3, \mathrm{R} \$ 125,86$.

Em (b), nas seis primeiras horas de irrigação, há somente os irrigantes 1 e 2 para a demanda de $0,65 \mathrm{~kW}$. Das 6 às 8 horas, com somente o irrigante 3, a demanda atinge 2,21 kW. No rateio simples, cada um pagará $\mathrm{R} \$ 19,50$ no mês. Na forma de rateio proposta, os irrigantes 1 e 2 pagariam $\mathrm{R} \$ 12,69$, e o terceiro, $\mathrm{R} \$ 33,12$.

Em (c), em que os três irrigantes trabalham separadamente, no rateio simples, cada um pagaria $\mathrm{R} \$ 16,20$ no mês. Na forma proposta, binômia, os irrigantes 1 e 2 pagariam $R \$ 5,46$, com o terceiro pagando $\mathrm{R} \$ 37,69$. 
Na Figura 2, apresentam-se, por gráficos, as três situações analisadas para a tarifa de rateio simples, hoje praticada, e a tarifa de rateio diferenciada pela pressão requerida, tarifa binômia para água.

Tarifa praticada

(1)
Tarifa proposta

(2)

త్ర
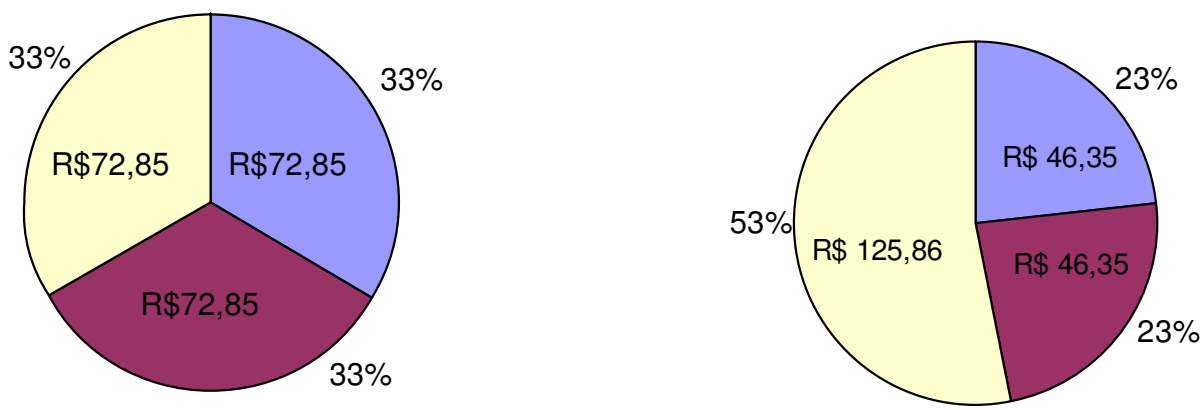

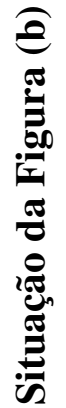
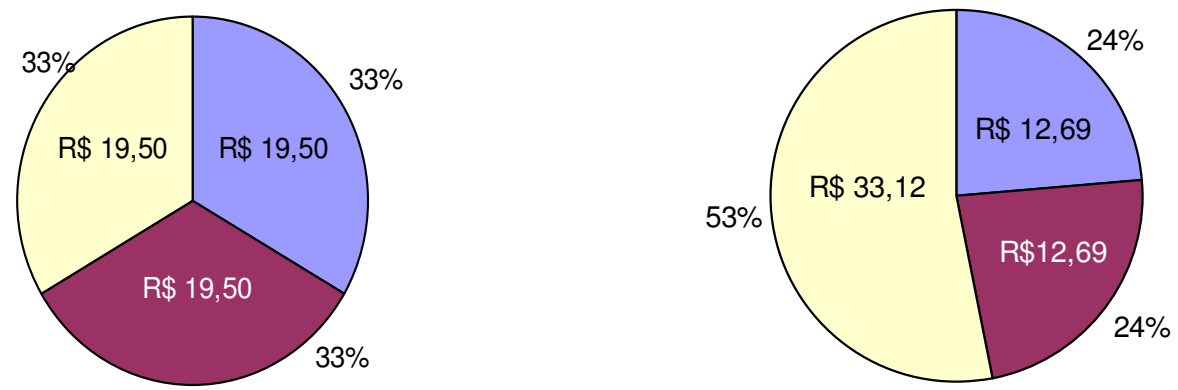

(0)
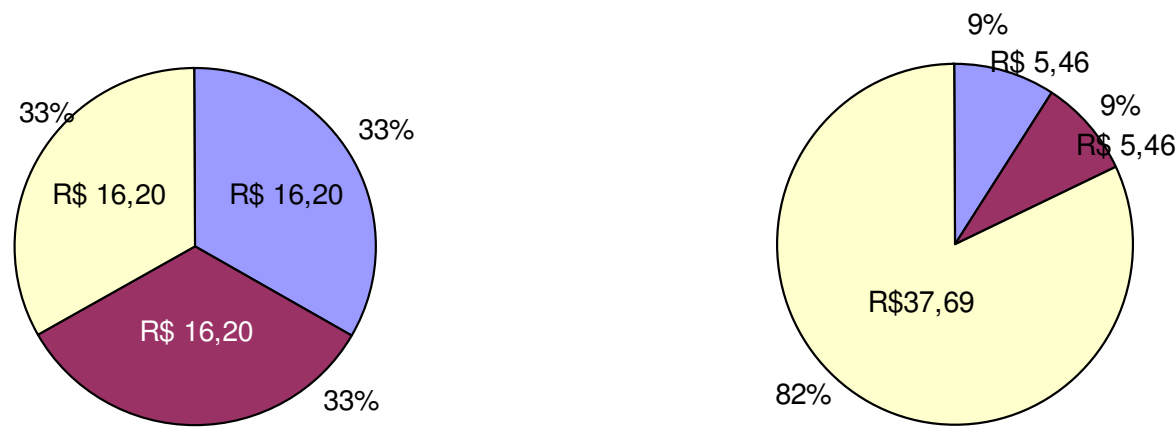

Legenda: $\square$ Irrigante $1 \square$ Irrigante 2 $\square$ Irrigante 3

FIGURA 2. Custo mensal de energia elétrica por rateio simples (coluna 1), e da forma proposta, tarifa binômia para água (coluna 2). Electricity monthly costs by simple division (column 1), and the proposal form, dual tariff for water, (column 2). 
Comparando-se a coluna (1) com tarifas de água pelo rateio simples da conta de energia elétrica e a coluna (2) com a forma proposta de rateio focada na pressão requerida pelo sistema do irrigante, pode-se observar que o modo de tarifação proposto:

- É um rateio mais justo por atribuir maior valor ao irrigante que mais onera a conta de energia e menores valores aos que menos oneram a conta;

- Estimula o uso de sistemas de irrigação de menor pressão por reduzir substancialmente a conta de energia elétrica;

- Induz à redução de coincidência de horários de irrigação por reduzir a pressão e a demanda de potência com minimização da conta de energia para todos.

\section{Medidas de gerenciamento e tarifas binômias}

Uma questão relevante a ser considerada é a de que irrigantes com sistemas de irrigação mais eficientes, e que não recebem incentivos para tal, poderiam ter descontos na conta de energia elétrica. A cobrança apenas da quantidade de água consumida em lote irrigado tem sido a prática mais comum, com penalização do irrigante eficiente. A forma proposta de tarifação binômia para o rateio da conta de energia elétrica de irrigação não só faz justiça aos que já utilizam meios eficientes como é, também, forma de estímulo para que outros reduzam sua conta, investindo em eficiência.

Na Tabela 3, apresenta-se comparação de sistemas de irrigação por aspersão convencional e por irrigação localizada para idênticas condições.

TABELA 3. Comparação de sistemas de irrigação por aspersão convencional e localizada. Irrigation systems comparison among conventional and localized methods.

\begin{tabular}{ccc}
\hline Produtor Irrigante A (aspersão) & & Produtor Irrigante B (localizada) \\
\hline Área irrigada & $=$ & Área irrigada \\
Lâmina de irrigação & $=$ & Lâmina de irrigação \\
Eficiência do sistema & $<$ & Eficiência do sistema \\
Pressão & $>$ & Pressão \\
Vazão & $>$ & Vazão \\
Tempo de irrigação & $<$ & Tempo de irrigação \\
Volume bombeado & $>$ & Volume bombeado \\
\hline
\end{tabular}

A aplicação de Tarifa Binômia na irrigação corrige a distorção existente do processo de rateio simples da conta de energia elétrica pelo volume em metros cúbicos de água bombeada, ou seja, reduz a conta de água dos irrigantes mais eficientes e aumenta a conta dos irrigantes menos eficientes, segundo a pressão utilizada em cada lote. Outra situação que poderia advir dessa aplicação, poderia ser a valoração dos lotes, em tempo de licitação, com preços diferenciados para a aquisição, segundo a diferença de nível em relação ao bombeamento.

\section{CONCLUSÕES}

Nos perímetros irrigados, em que o sistema de distribuição de água é pressurizado, é recomendável que, além da água, seja cobrada uma taxa referente ao custo de pressurização. Com isto, o irrigante com sistema de irrigação em maior pressão pagará mais do que aquele que trabalha com um sistema de menor pressão, representando maior justiça e estímulo ao uso racional de água e de eletricidade.

A aplicação da tarifa binômia em perímetros irrigados é um instrumento que aperfeiçoa a cobrança de insumos e serviços. Entretanto, depende da conscientização dos irrigantes, das mudança de normas que regem o perímetro, estatuto e regimento interno e de equipamentos para medição e registro de pressão. A migração dos produtores que utilizam sistemas de irrigação de 
baixa eficiência, ou tradicionais, para outros de maior eficiência, poderá acontecer como consequência da aplicação da tarifa binômia.

Logicamente, há custo para a substituição de sistema de aspersão convencional de média pressão por outro de irrigação localizada de baixa pressão. No entanto, com a utilização de tarifa binômia - diferenciada em relação à pressão demandada, a conta de energia do irrigante de baixa pressão apresentará substancial redução, o que poderá auxiliar a amortização do financiamento do novo sistema.

\section{REFERÊNCIAS}

ANA. AGÊNCIA NACIONAL DE ÁGUAS. O processo de outorga de águas e licenciamento ambiental para irrigação. Minicurso. In: CONGRESSO NACIONAL DE IRRIGAÇÃO E DRENAGEM, 12., 2002, Uberlância. Anais... Uberlândia: ANA, 2002.

BERNARDO, S.; SOARES, A.A.; MANTOVANI, E.C. Manual de irrigação. Viçosa, MG: Universidade Federal de Viçosa, 2006. 625 p.

BRASIL. Lei n $^{\circ}$ 9.433, de 8 de janeiro de 1997. Lei das águas. Diário Oficial da União, Brasília, DF, 8 jan. 1997.

COSTA, J.M. Análise exergética em sistemas elétricos. 2001. Dissertação (Doutorado em Engenharia Agrícola) - Universidade Federal de Viçosa, Viçosa - MG, 2001.

DNAEE. Departamento Nacional de Água e Energia Elétrica. Plano de comercialização para unidades consumidoras rurais com atividade predominante de irrigação. Brasília: DNAEE, 1988.

MAROUELLI, W.A.; SILVA, W.L.C. Seleção de sistemas de irrigação para hortaliças. Brasília: Embrapa-CNPH, 1998. 15 p. (Circular Técnica, 11).

MEDEIROS, S.S.; SOARES A.A.; RAMOS M.M.; MANTOVANI, E.C. ; SOUZA, J.A.A. Avaliação da eficiência do uso da energia elétrica no Perímetro Irrigado de Pirapora - MG. Revista Brasileira de Engenharia Agrícola e Ambiental, Campina Grande, v.7 n.2, p.394-398, 2003.

OLIVEIRA FILHO, D.; TANABE, C.S.; COSTA, J.M. Considerações da análise exergética em tarifas de energia elétrica. Revista Brasileira de Engenharia Agrícola Ambiental, Campina Grande, v.4, n.1, p.114-119, 2000.

RIBEIRO, M.C. Estudo sobre racionalização do uso de energia na irrigação. 2003. Dissertação (Mestrado em Engenharia Agrícola) - Universidade Federal de Viçosa, Viçosa - MG, 2003.

TANABE, C.S. Viabilidade da análise exergética na elaboração de tarifas de energia elétrica. Viçosa, MG: DEA/UFV, 1998. 72 f. Dissertação (Mestrado em Engenharia Agrícola) Universidade Federal de Viçosa, Viçosa - MG, 1998.

TURCO, J.E.P.; RIZZATTI, G.S.; PAVANI, L.C. Custo de energia elétrica em cultura do feijoeiro irrigado por pivô central, afetado pelo manejo da irrigação e sistemas de cultivo. Engenharia Agrícola, Jaboticabal, v.29, n.2, p.311-320, 2009. 